\title{
TRATAMENTO DE ESGOTO DOMÉSTICO A PARTIR DO SISTEMA LEITO DE RAÍZES: EXPERIÊNCIA EM UMA PEQUENA COMUNIDADE RURAL DO SEMIÁRIDO BRASILEIRO.
}

\section{Treatment of domestic sewage from the roots system: experience in a small rural community of the Brazilian Semi-arid.}

\section{Tratamiento de esgoto doméstico a partir del sistema lecto de raízes: experiencia en una pequeña comunidad rural del Semiárido Brasileño.}

\author{
Fabrício Oliveira Dias ${ }^{1}$ http://orcid.org/0000-0001-6671-7387 \\ Jémison Mattos dos Santos ${ }^{2}$ http://orcid.org/0000-0002-0934-4294 \\ Sampaio de Jesus ${ }^{3}$ http://orcid.org/0000-0002-3875-3695
}

\footnotetext{
${ }^{1}$ Licenciando em Geografia; Bolsista PROEX-UEFS-Feira de Santana-Bahia-Brasil. e-mail: fabriciogeo29@ gmail.com

${ }^{2}$ Doutor em Geografia; Professor do Departamento de Ciências Humanas e Filosofia-UEFS - Feira de Santana-Bahia-Brasil. Coordenador/Pesquisador do Projeto de Extensão Água da Vida. E-mail: jemisons@uefs.br

${ }^{3}$ Bacharelanda em Geografia; Bolsista PROEX-UEFS-Feira de Santana-Bahia-Brasil. e-mail: ssj.uefs@ @mail.com
}

\begin{abstract}
Resumo
O presente artigo aborda de forma sucinta a necessidade do manejo racional dos recursos hídricos e manejo ecológico da água no Semiárido Brasileiro, a partir da experiência de uma atividade extensionista na Escola Família Agrícola de Colônia, Itaetê-BA (EFACI), com o objetivo principal de realizar a instalação e operação de uma unidade experimental de tratamento de efluentes domésticos, por meio da técnica leito de raízes. Nesta etapa da pesquisa procedeu-se metodologicamente a execução de oficinas de capacitação com enfoque no planejamento ambiental participativo, manejo da água e do solo, bem como o tratamento de águas servidas, trabalhos de campo, com intuito de apresentar/compartilhar conteúdos técnicos e proporcionar a integração destes conhecimentos científicos com os saberes tradicionais da comunidade.
\end{abstract}

Palavras-chave: Estação de tratamento de efluentes. Popularização das ciências. Manejo ecológico da água.

\begin{abstract}
The present article succinctly discusses the need for rational management of water resources, and ecological management of water in the Brazilian Semi-arid, based on the experience of an extensionist activity at Escola Família Agrícola de Colônia, Itaetê-BA (EFACI), with the main objective of installation and operation of an experimental unit of treatment of domestic effluents, by means of the bed technique of roots. At this stage of the research, the implementation of training workshops focused on participatory environmental planning, water and soil management, as well as wastewater treatment, fieldwork. In order to present / share technical content and to provide the integration of this scientific knowledge with the traditional knowledge of the community.
\end{abstract}

Keywords: Effluent treatment plant. Popularization of sciences. Ecological management of water. 


\section{Resumen}

El presente artículo aborda de forma sucinta la necesidad del manejo racional de los recursos hídricos y el manejo ecológico del agua en el semiárido brasileño, a partir de la experiencia de una actividad extensionista en la Escuela Familia Agrícola de Colônia, Itaetê-BA (EFACI), con el objetivo principal de realizar la instalación y operación de una unidad experimental de tratamiento de efluentes domésticos, por medio de la técnica lecho de raíces. En esta etapa de la investigación se procedió metodológicamente la ejecución de talleres de capacitación con enfoque en la planificación ambiental participativa, manejo del agua y del suelo, así como el tratamiento de aguas servidas, trabajos de campo, con el propósito de presentar / compartir contenidos técnicos y proporcionar la integración de estos conocimientos científicos con los saberes tradicionales de la comunidad.

Palabras clave: Planta de tratamiento de efluentes. Popularización de las ciencias. Manejo ecológico del água.

Recebido em: 26 /10/2018

Aceito para publicação em: 19/12/2018

\section{Introdução}

A questão dos recursos hídricos é algo preocupante no semiárido brasileiro (SAB), principalmente, quando se observam dados mais recentes do Sistema Nacional de Informações sobre Saneamento (SNIS) das sedes municipais, bem como das áreas rurais.

$\mathrm{O}$ rol de atividades socioeconômicas desenvolvidas no SAB sem maior ou quase nenhuma preocupação ambiental e assistência técnica, somado às expressivas restrições educacionais, financeiras, tecnológicas e falta de conscientização em relação à importância do manejo da água e reuso das águas servidas, denotam os principais aspectos que caracterizam a maioria das pequenas comunidades do campo na região nordeste, e influenciam paulatinamente a perda crescente da qualidade das águas superficial, subterrânea e do solo (MEDEIROS, 2014; INSTITUTO TRATA BRASIL, 2016; QADIR \& SATO, 2016; JESUS, SANTOS, MATOS, 2018).

A pesquisa do Instituto Nacional do Semiárido (INSA) esclarece e reforça os argumentos da assertiva supracitada:

O índice de tratamento de esgoto, obtido da relação entre o volume de esgoto tratado e o coletado no Semiárido, alcançou $76,3 \%$, porém, ao considerar o volume total de esgoto produzido (423,3 milhões de $\mathrm{m}^{3} / \mathrm{ano}$ ), este percentual de tratamento não supera $21,1 \%$ (...) destacando, mais uma vez, a precariedade do sistema de esgotamento sanitário (MEDEIROS et. al, 2014, p. 46). 
Já os dados mais recentes do Instituto Trata Brasil $(2016)^{4}$ assinala que "apenas $45 \%$ do esgoto gerado no Brasil passa por tratamento. Isso quer dizer que os outros $55 \%$ são despejados diretamente na natureza, o que corresponde a 5,2 bilhões de metros cúbicos por ano ou quase 6 mil piscinas olímpicas de esgoto por dia".

Destaca ainda que "as fossas, sumidouros, valas a céu aberto e/ou lançamento direto nos corpos hídricos, constituem-se os principais destinos dos dejetos gerados, evidenciando a ausência de investimentos e a exposição dos habitantes a diversas doenças infecciosas e parasitárias" (MEDEIROS et. al, 2014).

A Escola Família Agrícola, encontra-se no espaço rural de Itaetê-BA, em uma localidade conhecida como Colônia, Território de Identidade Chapada Diamantina. Nesta escola são assistidas cerca de 50 pessoas (entre jovens, crianças e professores), onde são realizadas diversas atividades escolares e práticas rurais em tempo integral.

A ação extensionista que define este trabalho, em questão, caracteriza-se pela ampliação, integração e popularização das ciências, e almeja contribuir com o planejamento ambiental e gestão dos recursos hídricos em pequenas comunidades rurais de Itaetê.

Este estudo é parte de um projeto maior de extensão denominado “ÁGUA DÁ VIDA: O RIO QUE VAI, TRAZ A VIDA TAMBÉM” que é apoiado pela Pró-Reitoria de Extensão (PROEX), a partir do Programa Institucional de Bolsas de Extensão (PIBEX) e também pelo Laboratório de Estudos da Dinâmica e Gestão de Ambiente Tropical (GEOTRÓPICOS) e sua equipe de pesquisadores, bem como pelos lideres comunitários e professores da EFACI.

O objetivo primordial é contribuir com o manejo ecológico da água na comunidade a partir da experiência de instalação e operação de uma unidade experimental de tratamento de efluentes domésticos, utilizando a técnica de leito de raízes. Além disso, busca-se capacitar e sensibilizar os atores diversos da EFACI, a respeito da necessidade do manejo racional dos recursos hídricos diante da situação ambiental observada in loco, a exemplo do despejo de águas servidas diretamente no solo, a ausência de estações de tratamento de esgoto doméstico. Rol de problemas ambientais que potencializam a incidência de doenças veiculadas hidricamente.

O sistema proposto em questão é reconhecido pela eficiência e utilizado há mais de 100 anos na Europa. O sistema tem passado por adaptações para atender as diversas condições de clima existentes principalmente nos Estados Unidos, Austrália e no Brasil. Com as técnicas do filtro anaeróbio é possível alinhar a vantagem do filtro biológico aeróbio, com maior

\footnotetext{
${ }^{4} \mathrm{O}$ estudo é feito com base nos dados mais recentes do Sistema Nacional de Informações sobre Saneamento (SNIS), que se referem ao ano de 2016.
} 
Tratamento de esgoto doméstico a partir do sistema leito de raízes: experiência em uma pequena comunidade rural do semiárido brasileiro.

DIAS, F. O. D.; SANTOS, J. M. dos; JESUS, S. S. de

capacidade de depuração da carga orgânica, Nitrogênio e Fósforo, com menor tempo de retenção (LIMA, 2017).

Ressalta-se que o fundamento desta pesquisa se dá com base na realização de oficinas para que haja apreensão dos conteúdos de maneira satisfatória e a integração dos conhecimentos científicos com os saberes tradicionais, com intuito de compreender a realidade local através das temáticas do saneamento rural, da conservação da água e do solo. Além de promover discussões/debates abertos a toda comunidade, relacionados com as temáticas em questão, a fim de identificar, interpretar, analisar os principais problemas relacionados ao manejo da água e do solo ocorrentes na EFACI e entorno.

\section{O sistema de leito de raízes no tratamento de efluentes}

O lançamento indiscriminado de águas servidas no Brasil pode ser considerado um dos maiores problemas ambientais e de saúde pública. Por isso que o tratamento de águas servidas em pequenas comunidades rurais por meio da supracitada técnica, com a utilização de plantas adaptadas ao clima semiárido, constitui-se uma iniciativa fundamental para auxiliar o desenvolvimento do saneamento básico rural.

O sistema de leito (zona) de raízes é uma técnica de baixo custo e simples manuseio que permite melhorar a qualidade da água e do solo, com efeitos positivos na qualidade socioambiental da bacia do rio Una-Ba onde encontra-se a EFACI. Com base em Sallati (2003) "são diversas às utilidades encontradas no tratamento de águas servidas favorecendo sempre a proteção do ambiente".

A poluição e/ou contaminação das águas são duas questões cruciais para serem analisadas no contexto da região semiárida brasileira. Esta, que apresenta no seu histórico, aspectos negativos, tanto sociais quanto ambientais frente à temática dos recursos hídricos.

Grande parte dos problemas é fruto do processo ineficiente de planejamento somado à inexpressiva gestão do ambiente semiárido baiano nas esferas públicas estadual e municipal, aliado aos prolongados períodos de escassez hídrica em alguns municípios nordestinos, a exemplo de Itaetê, agudizando o cenário de secas e desigualdades sociais que marcam historicamente o sertão baiano. Além disso, compreende-se que existem outros entraves do ponto de vista tecnológico e cultural.

Por meio de um conjunto de atividades práticas realizadas na EFACI durante a oficina fez-se à identificação e exposição dos principais problemas ambientais locais, contribuindo para que grande parte dos estudantes e até professores (que residem nesta comunidade e 
Tratamento de esgoto doméstico a partir do sistema leito de raízes: experiência em uma pequena comunidade rural do semiárido brasileiro.

DIAS, F. O. D.; SANTOS, J. M. dos; JESUS, S. S. de

outras do entorno), pudessem refletir sobre as formas de manejo da água e assim perceber facilmente que o esgoto doméstico tem sido descartado de modo impróprio; na superfície do solo e em fossas negras, podendo causar alterações drásticas no ambiente (p.ex: contaminação da água subterrânea e do solo) ( painel 1).

Portanto, devido ao conjunto de especificidades e benesses, compreende-se que a instalação da Estação de Tratamento de Efluentes Domésticos a partir do Sistema Leito de Raízes (ETEDZR) na EFACI será de grande relevância para comunidade, e seguramente produzirá melhorias do ponto de vista socioambiental.

Painel 1- Fotos da palestra e minicurso com estudantes e professores da EFACI - Itaeté - 2017

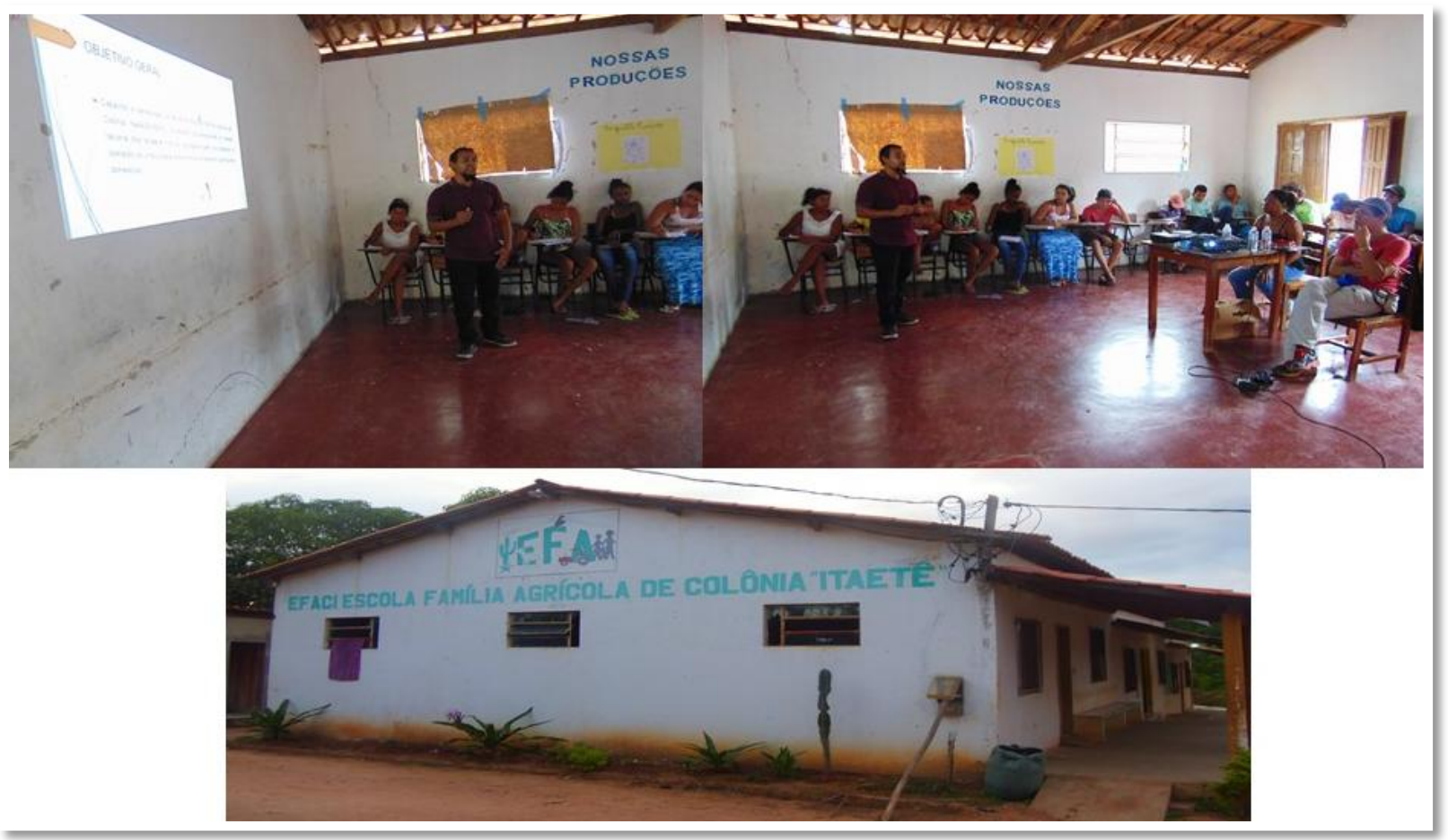

Fonte: trabalho de campo fotos - JESUS, Suílian. S. de. \& SANTOS, Jémison. M. dos. 2017.

Dentre as técnicas consultadas entende-se que uma das melhores alternativas para o saneamento rural no $\mathrm{SAB}$, de maneira sustentável, está o leito de raízes. São ditos sistemas naturais, pois se baseiam na capacidade de ciclagem de elementos contidos na água residuária sem fornecimento de qualquer fonte de energia para acelerar os processos biogeoquímicos, os quais ocorrem de forma espontânea (OLIJNYK et al., 2007).

Triverdy (2007) caracteriza mais precisamente a referida técnica a ser empregada na EFACI:

O conceito de tecnologia de zona de raiz é baseado na capacidade bem conhecida das plantas e sua rizosfera associada para concentrar e/ou degradar contaminantes altamente diluídos. Certas plantas de áreas úmidas funcionam naturalmente como uma bomba biológica. Suas folhas e caules 
Tratamento de esgoto doméstico a partir do sistema leito de raízes: experiência em uma pequena comunidade rural do semiárido brasileiro.

DIAS, F. O. D.; SANTOS, J. M. dos; JESUS, S. S. de

absorvem oxigênio da atmosfera e o transfere através de seus caules e raízes. As partes macias das raízes, através de suas membranas, transferem esse oxigênio para o solo. O oxigênio assim liberado é muito ativo e está disponível para microrganismos no solo para prosperar e se multiplicar. Se o efluente contendo matéria orgânica for passado por percolação nesta zona, a população bacteriana consome essa matéria orgânica e purifica o efluente. Essa ação ocorre em áreas úmidas naturais, mas com menos eficiência.

Baseado em Kaick (2012), observa-se um perfil estrutural da estação de tratamento de esgoto doméstico sustentável.

Ilustração 1 - Perfil Estrutural de uma Estação de Tratamento de Esgotos (ETEDZR)

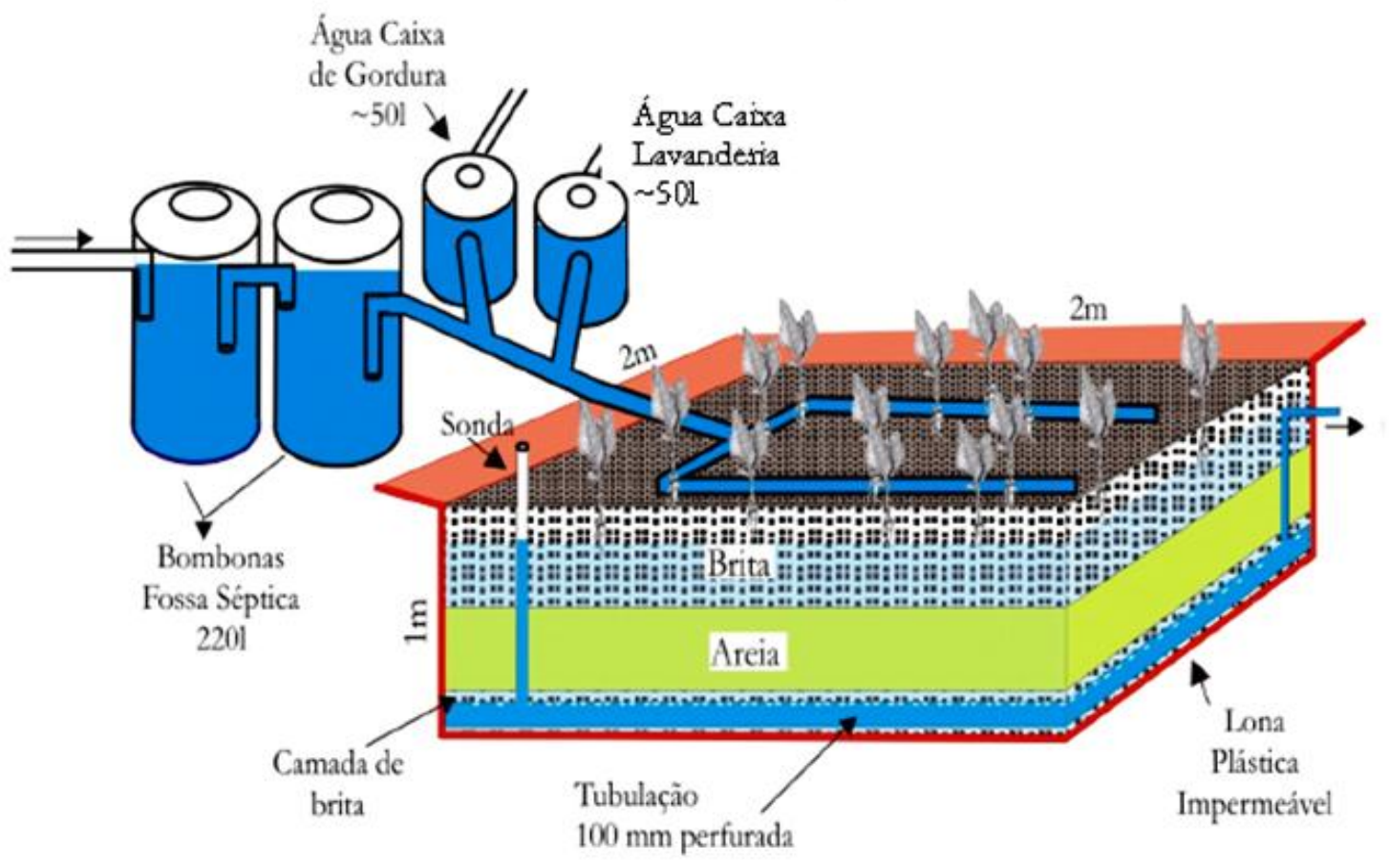

Fonte: PAROLIN, CRISPIM E KAICK (2012).

Ao observar as fotos do painel 2, é possível entender passo a passo como deve ser efetuado o processo de construção de uma ETEDZR. 
Tratamento de esgoto doméstico a partir do sistema leito de raízes: experiência em uma pequena comunidade rural do semiárido brasileiro.

DIAS, F. O. D.; SANTOS, J. M. dos; JESUS, S. S. de

Painel 2 - Construção passo a passo de uma ETEDZR na zona rural

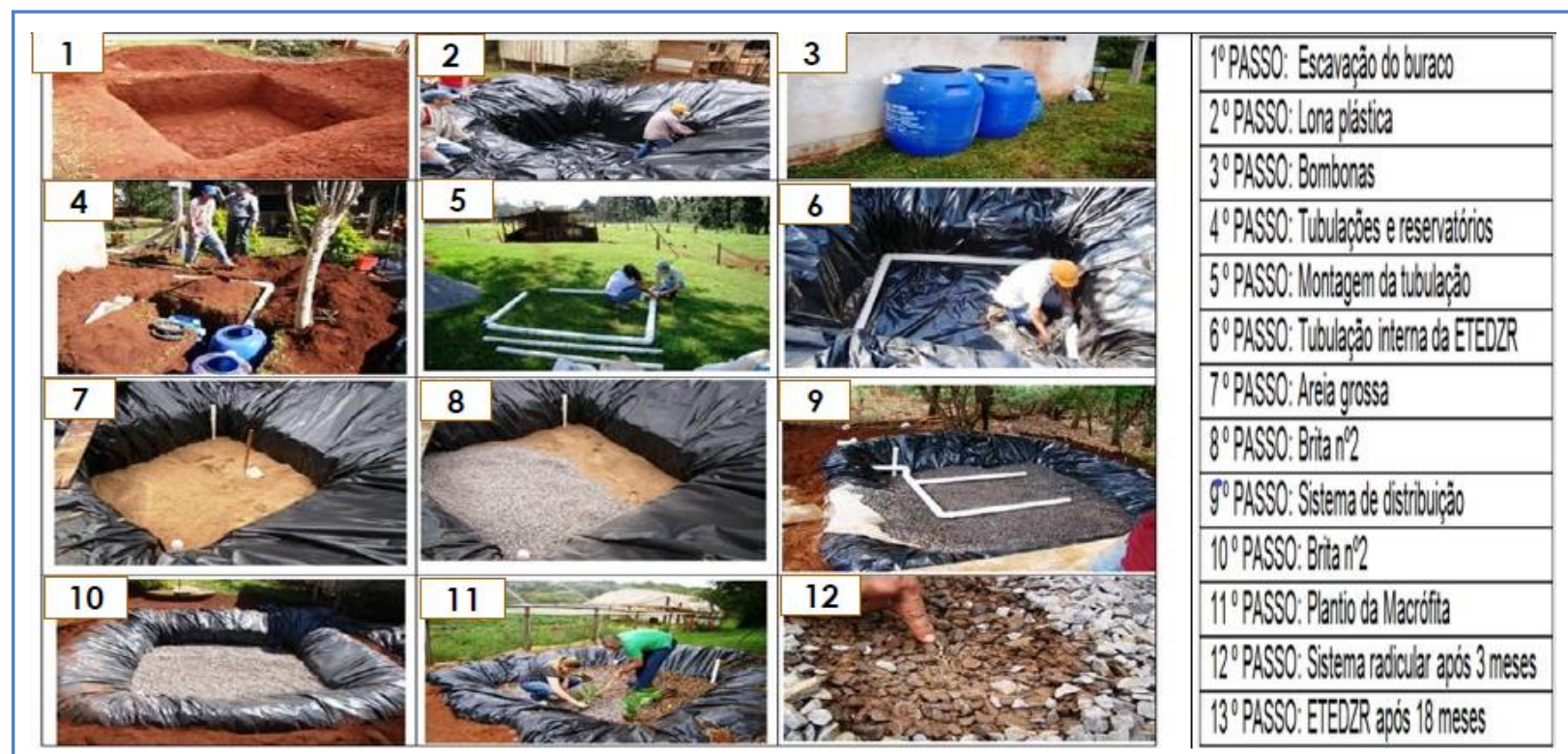

Resultado da estação de tratamento de efluentes domésticos por leito de raízes após 18 meses

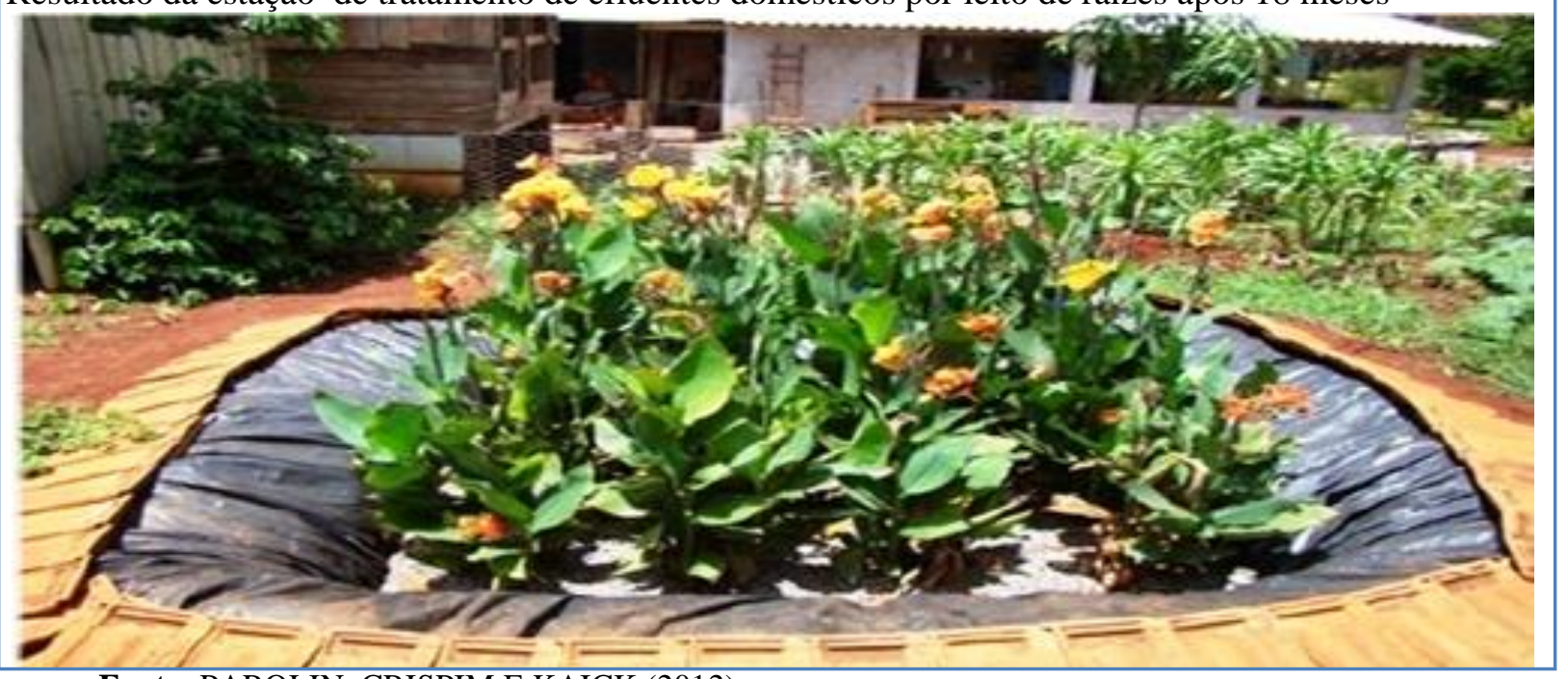

Fonte: PAROLIN, CRISPIM E KAICK (2012).

Este sistema se destaca pela eficiência no processo de degradação da matéria orgânica, pois é muito completo devido à grande biomassa e ainda contribui na remoção de nutrientes como fósforo e nitrogênio (SALLATI, 2003).

$\mathrm{Na}$ perspectiva de complementar o conceito anterior, foram observadas as demais formas de utilização dos leitos de raízes:

"Os sistemas zonas de raízes, construídos, podem ser utilizados como: tratamento integral do esgoto doméstico; tratamento secundário e terciário de esgoto; tratamento de efluentes agrícolas; barreiras de retenção; recuperação de áreas alagadas; entre outros" (SALATTI, 2003, p.39).

Logo, a construção e a popularização desta unidade experimental de tratamento de águas servidas contribuirão para que os corpos hídricos das comunidades rurais não sejam poluídos. Pois, recomenda-se que os efluentes de qualquer fonte poluidora somente poderão 
Tratamento de esgoto doméstico a partir do sistema leito de raízes: experiência em uma pequena comunidade rural do semiárido brasileiro.

DIAS, F. O. D.; SANTOS, J. M. dos; JESUS, S. S. de

ser lançados, direto ou indiretamente, nos corpos de água, após o devido tratamento. Sobre a poluição das águas Von Sperling (1996) afirma que:

A poluição das águas é a adição de substâncias ou de forma de energia que, direta ou indiretamente, alterem a natureza do corpo d'água de uma maneira tal que prejudique os legítimos usos que delas são feitos (VON SPERLING, 1996).

Seguindo o raciocínio do autor ao definir a poluição das águas reflete-se que, este assunto infelizmente faz parte da realidade das inúmeras comunidades rurais do Estado da Bahia (lançamento indiscriminado de esgotos sem tratamento prévio nos corpos hídricos). Por conta disso, em Itaetê como em muitas outras comunidades, percebe-se que o saneamento rural ainda vai demorar muito tempo para ser implantado.

Observou-se também que a priori, a coleta de água em poços artesianos é alternativa mais viável para o consumo local. Sendo assim, a ausência de estações de tratamento de efluentes domésticos nesta área rural deve ser vista como um sério problema ambiental, que deve ser enfrentado a partir da utilização de tecnologias eficientes e de baixo custo, de preferência financiadas pelos setores públicos estaduais, municipais e até privados.

As discussões travadas nas oficinas envolvendo os aspectos e impactos socioambientais locais almejam descortinar a realidade vivida na EFACI, ou seja, compreender mais claramente a problemática local e elencar as principais ações socioeconômicas que podem a médio e longo prazo causar degradação ambiental p.ex: a existência de uma fossa negra, localizada a menos de 20 metros de um ponto de captação de água (poço artesiano). Por meio deste aspecto ambiental os estudantes e professores puderam refletir que caso o esgoto não seja descartado e tratado adequadamente, consequentemente ocorrerá a contaminacão do solo e corpos hídricos (rios, lençóis freáticos), além de ocasionar doenças que podem afetar a saúde das pessoas.

Este trabalho extensionista tem produzido informações mais consistentes e reflexões sobre as formas mais satisfatórias de manejo da água, além de compartilhar conhecimentos científicos e colocar em evidência a necessidade premente do manejo sustentável das águas servidas em pequenas comunidades rurais do $\mathrm{SAB}$, bem como revela algumas alternativas viáveis economicamente que podem contribuir de forma positiva com a segurança alimentar na EFACI. Por exemplo, sugere-se introduzir posteriormente à irrigação com o esgoto tratado e avaliar os impactos no solo, aquífero e os efeitos na planta.

Para tal propósito, deve-se proceder à avaliação química e física do esgoto após passar pela estação de tratamento de efluentes, visando o reuso deste nas diversas atividades agrícolas realizadas na EFACI (um dos próximos passos da pesquisa). 
Por meio dessa atividade extensionista notou-se também a necessidade de realização de pesquisas mais aprofundadas e interdisciplinares sobre a poluição/contaminação dos corpos hídricos, dos solos e a incidência de doenças veiculadas pela água (principalmente nas crianças). Uma vez que é notório o despejo dos efluentes domésticos na comunidade, em foco, bem como o descarte de resíduos sólidos de forma inadequada.

\section{Considerações finais}

Confirma-se que o manejo inadequado das águas servidas, o descarte de efluentes nos solos e a ausência do saneamento básico na EFACI constituem-se graves problemas locais, que ainda não foram solucionados. Uma vez que a inexistência de estações de tratamento de efluentes domésticos contribui decisivamente para a poluição e a possível contaminação dos corpos hídricos superficiais e subterrâneos, dos solos e a propagação de patologias veiculadas hidricamente.

Dentre as alternativas para equacionar as questões supracitadas, sinaliza-se destacadamente o uso e a aplicação da técnica de tratamento de efluentes domésticos por meio do sistema de leito de raízes/leitos cultivados, devido ao baixo custo de implantação, o reduzido consumo de energia e manutenção, bem como por ser um sistema relativamente simples de construir. Além disso, a promoção de melhorias das condições sanitárias e estéticas na paisagem.

Dessa maneira é possível afirmar que esta fase do estudo (extensão) foi efetuada com êxito devendo dar continuidade a próxima etapa, que envolverá o processo de instalação e operação da ETEDZR, a partir de um mutirão na comunidade.

Por fim, chamam-se a atenção aos atores da EFACI e demais comunidades rurais do SAB para a importância do manejo adequado das águas servidas a fim de evitar problemas socioambientais mais agigantados em um futuro próximo.

\section{Referências}

ANA. Agência Nacional de Águas. Disponível em: http://www 2.ana .gov .br /Páginas/imprenas/ not icia.aspx?idnoticia=12525. Acessso em 20 de fevereiro de 2017.

COSTA FILHO, A. G. Aplicação de sistemas alternativos para o tratamento de esgoto em áreas de mananciais em Santo André - Wetland. Disponível em: <http://www.semasa.sp.gov.br/Documentos/ASSEMAE/Trab_56.pdf>. Acesso em: 25 ago. 2004. 
Tratamento de esgoto doméstico a partir do sistema leito de raízes: experiência em uma pequena comunidade rural do semiárido brasileiro.

DIAS, F. O. D.; SANTOS, J. M. dos; JESUS, S. S. de

DUARTE, Renato. Dois modelos para a convivência do produtor rural com o ambiente do semi-árido nordestino.TPD n. 109, Recife. Fundação Joaquim Nabuco, Março, 2001.

Disponível em: https://fundaj.emnuvens.com.br/TPD/article/view/924/645. Acesso em 20 de fevereiro de 2017.

ESTEVES, F. A. Fundamentos de Limnologia. 2 ed. Rio de Janeiro: Interciência/FINEP, 1998. 602p.

INSTITUTO TRATA BRASIL. Ranking-do-saneamento, 2016. Disponível em: http://www.tratabrasil.org.br/component/estudos/itb/ranking-do-saneamento-2016. Acesso em 10 de maio de 2017.

KAICK, T. S. V. PAROLIN, M. CRISPIM, J. Q. Tratamento de esgoto por zona de raízes: análise e eficiência. Revista GEOMAE - Geografia, Meio Ambiente e Ensino. Vol. 03, No 01, Campo Mourao, Felicam 2012.

KAICK, T. S. V. Estação de tratamento de esgoto por meio de zona de raízes: uma proposta de tecnologia apropriada para saneamento básico no litoral do Paraná. 2002. 128 f.

Dissertação (Mestrado em Tecnologia) - Universidade Tecnológica Federal do Paraná, Curitiba, 2002.

LIMA, Rodrigo Fidelis de Souza. Potencialidades dos wetlands construídos empregados no pós-tratamento de esgotos: experiências brasileiras. Dissertação (Mestrado em engenharia ambiental) Florianopolis, UFSC, 2016.

MEDEIROS, S de Souza (et. al). Esgotamento Sanitário Panorama para o Semiárido Brasileiro. Campina Grande: INSA, 2014. 63p. Disponível em:

https://portal.insa.gov.br/acervo-livros/187-esgotamento-sanitario-panorama-para-osemiarido-brasileiro. Acesso em 20 de fevereiro de 2017.

OLIJNYK, Débora Parcias (et. al). Sistemas de tratamento de esgoto por zona de raízes: análise comparativa de sistemas instalados no Estado de Santa Catarina. Anais: $24^{\circ}$ Congresso Brasileiro de Engenharia Sanitária e Ambiental. 2007. Belo Horizonte. Anais... Rio de Janeiro: ABES, 2007. 1 CD-ROM.

QADIR .M \& SATO, T. Water reuse in arid zones. Urban water Reuse Handbook, pp. 867$874,2016$.

SALATI, Eneas; SALATI FILHO, Eneas; SALATI, Eneida. Utilização de sistemas de wetlands construídas para tratamento de águas. Piracicaba: Instituto Terramax 2009.

JESUS, Suílian Sampaio; SANTOS, Jémison Mattos dos; MATOS, Ângela Carine Felix de Oliveira. A experiência do monitoramento hidroclimático em um projeto de extensão com a escola família agrícola e o assentamento do baixão, itaetê-ba. Geopauta, [S.1.], v. 2, n. 2, p. 27-37, ago. 2018. ISSN 2594-5033. Disponível em:

<http://periodicos2.uesb.br/index.php/geo/article/view/4025>. Acesso em: 18 set. 2018. doi: https://doi.org/10.22481/rg.v2i2.4025.

TRIVERDY, R. K. "Low cost and energy saving technologies for water and wastewater treatment”, Journal of Industrial Pollution Control, 23 (2), pp. 403-411, 2007. 
VON SPERLING, Marcos. Introdução à qualidade das águas e ao tratamento de esgotos. 3.ed. Belo Horizonte: Departamento de Engenharia Sanitária e Ambiental; Universidade Federal de Minas Gerais; 1996. p. 15 - 48.

\section{Agradecimentos}

Agradecemos a equipe de pesquisa do Laboratório de Estudos da Dinâmica e Gestão de Ambiente Tropical (GEOTRÓPICOS-UEFS), também Dona Vera (liderança feminina exemplar e solidária) em nome da comunidade da EFACI pelo acolhimento e parceria dedicada. E ao programa de Bolsas de Iniciação Científica da PROEX-UEFS.

O referido estudo contou também com o apoio GEOTRÓPICOS, por meio da infraestrutura e instrumentos de precisão (GPS, computadores, mapas, bibliografias, etc.). E ao motorista da UEFS, caro Leomar pelo excelente serviço prestado, que foi além da direção corriqueira (amizade em construção com um profissional atento, curioso, parceiro e disposto a auxiliar coletivamente nos desafios que surgem em uma atividade de campo dessa natureza). 